\title{
On the Role of the Eastern Pacific Teleconnection in ENSO Impacts on Wintertime Weather over East Asia and North America ${ }^{0}$
}

\author{
YING DAI ${ }^{\mathrm{a}}$ AND BENKUI TAN \\ Department of Atmospheric and Oceanic Sciences, School of Physics, Peking University, Beijing, China
}

(Manuscript received 18 November 2017, in final form 5 December 2018)

\begin{abstract}
Previous studies have mainly focused on the influence of El Niño-Southern Oscillation (ENSO) on seasonal-mean conditions over East Asia and North America. This study, instead, proposes an ENSO pathway that influences the weather events over East Asia and North America, in which the eastern Pacific teleconnection pattern (EP) plays an important role. On the one hand, the EP pattern can induce significant surface temperature anomalies over East Asia during its development and mature stages, with the positive (negative) EPs causing colder (warmer) than normal weather events. Besides, the frequency of occurrence of EPs is significantly modulated by ENSO, with $50 \%$ of the positive EPs occurring in La Niña winters, and $47 \%$ of the negative EPs occurring in El Niño winters. As a result, in El Niño winters, more negative and fewer positive EPs tend to occur, and thus more warm and fewer cold weather events are expected in East Asia. For La Niña winters, the reverse is true. On the other hand, for the EP pattern without its canonical convection pattern (referred to as the nonconvective EP), extremely cold anomalies over the northern United States and western Canada are induced in its negative phase. Moreover, when there are positive sea surface temperature anomalies in the central equatorial Pacific, the frequency of occurrence of negative nonconvective EPs is 2.0 times greater than the climatological value, and thus an enhanced likelihood of extremely cold spells over North America may be expected.
\end{abstract}

\section{Introduction}

El Niño-Southern Oscillation (ENSO) is the dominant pattern of large-scale variability in the tropical Pacific that has global impacts on precipitation and surface temperature patterns that are of great relevance to society (Ropelewski and Halpert 1987; Halpert and Ropelewski 1992; Trenberth et al. 1998; Yeh et al. 2018). Previous studies have explored the downstream (with respect to the direction of the midlatitude westerlies) impacts of ENSO on North American climate (Ropelewski and Halpert 1986; Green et al. 1997), where the role of the Pacific-North American (PNA) teleconnection has been emphasized (Wallace and Gutzler 1981; Horel and

Supplemental information related to this paper is available at the Journals Online website: https://doi.org/10.1175/JCLID-17-0789.s1.

\footnotetext{
${ }^{\text {a }}$ Current affiliation: Max Planck Institute for Meteorology, Hamburg, Germany.
}

Corresponding author: Benkui Tan, bktan@pku.edu.cn
Wallace 1981; Barnston and Livezey 1987; Renwick and Wallace 1996; Linkin and Nigam 2008).

Additionally, ENSO also exerts significant impacts on the upstream climate in East Asia through modulating the East Asian winter monsoon (EAWM), which is the most influential system of wintertime East Asia (Huang et al. 2007; Huang et al. 2012). An out-of-phase relationship between ENSO and EAWM has been documented (Li 1990; Webster and Yang 1992; Zhang et al. 1996; Chen et al. 2000; Lau and Nath 2000; Wang et al. 2000). Specifically, EAWM weakens in El Niño winters and strengthens in La Niña winters. Further studies reveal that the generally accepted ENSO-EAWM relationship varies with the phases of ENSO, the phases of the Pacific decadal oscillation (PDO), and the ENSOPDO phase combinations. In particular, Zhang et al. (2015) demonstrated that El Niño can weaken the EAWM significantly, but the La Niña impact on the EAWM is weak and insignificant. Wang et al. (2008) suggested that there is no significant relationship between ENSO and the EAWM when the PDO is in its high phase; in contrast, in the low phase of the PDO, ENSO exerts a strong impact on the EAWM. Kim et al. 
(2014) showed that there is a significantly intensified negative relationship between ENSO and the EAWM when ENSO and the PDO are in in-phase combinations; in contrast, when the ENSO and PDO are in out-ofphase combinations, the relationship is insignificant. As to the mechanisms responsible for the out-of-phase relationship between ENSO and EAWM, Li (1990) demonstrated that El Niño events can weaken the East Asia winter monsoon through enhancing the climatological westerlies in the midlatitudes, which is unfavorable for the southward intrusion of cold waves. Wang et al. (2000) suggested that the effects of ENSO on the EAWM are realized through the Pacific-East Asian teleconnection, where an anomalous lower-tropospheric anticyclone (cyclone) located in the western North Pacific plays the key role in weakening (enhancing) East Asian winter monsoons in El Niño (La Niña) winters by inducing anomalous southerlies (northerlies) along the coast of East Asia.

The studies mentioned above reveal that, through atmospheric teleconnections, such as the Pacific-East Asian teleconnection (Wang et al. 2000) and the PacificNorth American teleconnection (Wallace and Gutzler 1981; Horel and Wallace 1981), ENSO influences wintertime climate over East Asia and North America, respectively. However, the influence of ENSO on weather events of two weeks or so in wintertime East Asia and North America remains unclear. Are they influenced by ENSO as well? And if so, what are the underlying processes? These questions are of great importance to improve medium- and extended-range weather predictions, and are the subject of the present study.

This study proposes a new pathway responsible for the impacts of ENSO on wintertime weather over East Asia and North America, where the eastern Pacific (EP) teleconnection pattern plays a crucial role. The EP pattern is a recently detected teleconnection pattern in the wintertime North Pacific that has an intrinsic time scale of two weeks or so (Athanasiadis et al. 2010; Tan et al. 2015; Yuan et al. 2015). It is characterized in the upper troposphere by two primary centers over North Pacific and two secondary centers over North Asia and the subtropical Pacific (Fig. 1a). An early study (Tan et al. 2015) showed that the EP pattern may be driven by an anomalous tropical convection dipole, with one extremum located over the Maritime Continent and the other over the central equatorial Pacific (hereafter denoted as EP's canonical convection pattern) (Fig. 1b). In addition, previous studies also emphasized the role of midlatitude transient eddies in generating the EP pattern, with the high-frequency transient eddies contributing to its growth and maintenance (Athanasiadis et al. 2010; Tan et al. 2015), and the low-frequency transient
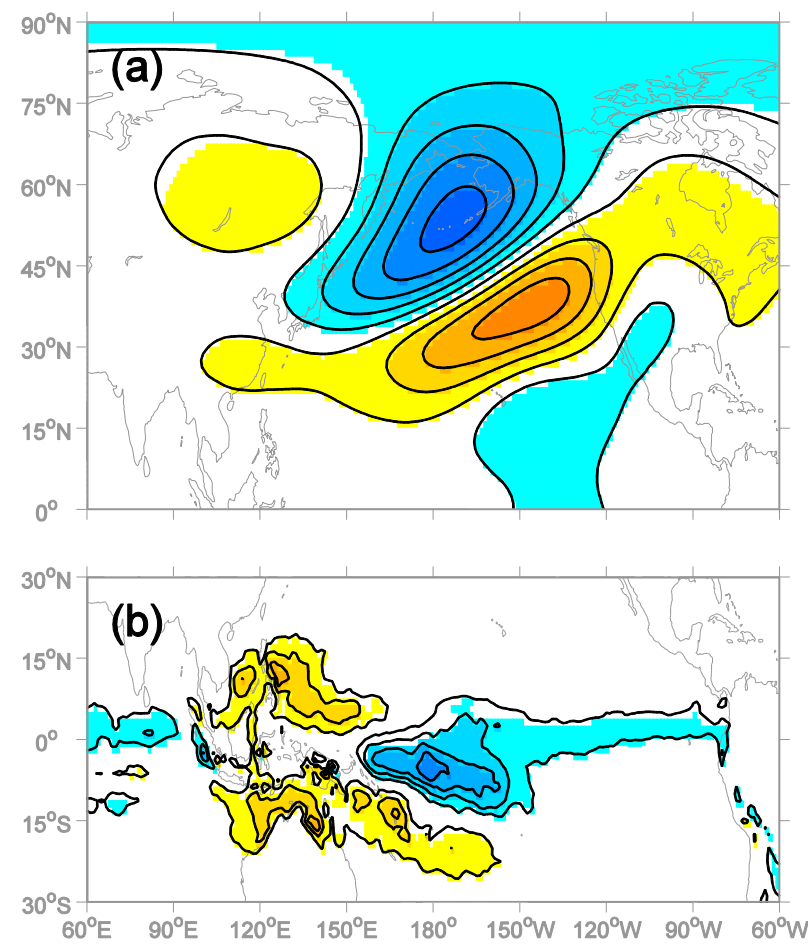

FIG. 1. (a) Simultaneous regressions of unfiltered daily $250-\mathrm{hPa}$ anomalous geopotential heights and (b) 2-week mean (over the period from day -13 to day 0 ) of lagged regressions of unfiltered daily $250-\mathrm{hPa}$ convective heating rate anomalies against EPI. For geopotential height anomalies, contours start from $\pm 10 \mathrm{~m}$ with an interval of $20 \mathrm{~m}$. For convective heating rate anomalies, contours start from $\pm 0.1 \mathrm{~K} \mathrm{day}^{-1}$ with an interval of $0.1 \mathrm{~K} \mathrm{day}^{-1}$. Warm (cold) shadings indicate positive (negative) anomalies that are statistically significant at the $p<0.01$ level as determined with a two-tailed Student's $t$ test.

eddies contributing to its growth and decay (Tan et al. 2015). However, they did not distinguish between EP patterns that are preceded by tropical convection and those that are not. Hereafter, we refer to the EP patterns associated with EP's canonical convection pattern as the convective EP, and those unrelated to EP's canonical convection pattern as the nonconvective EP. For the convective EP, one may expect a strong linkage of this type of EP to tropical convection, and hence a significant modulation of this type of EP by ENSO, which may be of particular interest for medium- and extended-range predictions. By contrast, for the nonconvective EP, one may expect driving by transient eddy fluxes to take on a more prominent role than occurs during the life cycles of the convective EP. To assess whether this is indeed the case, in this study, instead of combining the convective and nonconvective EP in the analyses, we investigate separately the formation mechanisms of the two types of EPs. On the basis of that, this study further investigates how both types of EPs affect wintertime weather over 
TABLE 1. The number and frequency (unit: events per winter) of EP events detected in different ENSO phases for the extended winter (NDJFM) over 1958/59-2014/15. El Niño, La Niña, and ENSO-neutral stand for the warm, cold, and neutral phases of ENSO, respectively; a plus sign $(+)$ represents the positive phase and a minus sign $(-)$ the negative phase of EPs. Frequency marked with an asterisk $(*)$ is statistically significant with respect to the climatology at the $p<0.10$ level on a two-tailed Monte Carlo test, while frequency with a superscript number sign $\left(^{\#}\right)$ is significantly different between El Niño and La Niña winters at the $p<0.10$ level on a two-tailed Monte Carlo test. Events that meet none of the thresholds used to distinguish the convective and nonconvective EP events are discarded.

\begin{tabular}{|c|c|c|c|c|}
\hline 1958/59-2014/15 & All winters & El Niño ${ }^{a}$ & La Niñab & ENSO-neutral $^{c}$ \\
\hline $\mathrm{EP}^{+}$ & $116(2.04)$ & $23(1.15)^{* \#}$ & $58(3.22)^{* \#}$ & $35(1.84)$ \\
\hline Nonconvective $\mathrm{EP}^{+}$ & $48(0.84)$ & $12(0.60)$ & $11(0.61)$ & $25(1.32)^{*}$ \\
\hline Convective $\mathrm{EP}^{+}$ & $46(0.81)$ & $1(0.05)^{* \#}$ & $41(2.28)^{* \#}$ & $4(0.21)^{*}$ \\
\hline $\mathrm{EP}^{-}$ & $116(2.04)$ & $54(2.70)^{* \#}$ & $20(1.11)^{* \#}$ & $42(2.21)$ \\
\hline Nonconvective $\mathrm{EP}^{-}$ & $42(0.74)$ & $10(0.50)$ & $6(0.33)^{*}$ & $26(1.37)^{*}$ \\
\hline Convective $\mathrm{EP}^{-}$ & $46(0.81)$ & $38(1.90)^{* \#}$ & $1(0.06)^{* \#}$ & $7(0.37)^{*}$ \\
\hline
\end{tabular}

${ }^{a}$ The 20 El Niño winters are 1958/59, 1963/64, 1965/66, 1968/69, 1969/70, 1972/73, 1976/77, 1977/78, 1979/80, 1982/83, 1986/87, 1987/88, 1991/92, 1994/95, 1997/98, 2002/03, 2004/05, 2006/07, 2009/10, and 2014/15.

b The 18 La Niña winters are 1964/65, 1967/68, 1970/71, 1971/72, 1973/74, 1974/75, 1975/76, 1984/85, 1988/89, 1995/96, 1998/99, 1999/00, 2000/01, 2005/06, 2007/08, 2008/09, 2010/11, and 2011/12.

${ }^{c}$ The 19 ENSO-neutral winters are 1959/60, 1960/61, 1961/62, 1962/63, 1966/67, 1978/79, 1980/81, 1981/82, 1983/84, 1985/86, 1989/90, 1990/ 91, 1992/93, 1993/94, 1996/97, 2001/02, 2003/04, 2012/13, and 2013/14.

East Asia and North America, and how they are modulated by ENSO. It turns out these two types of EP patterns show remarkable differences in formation mechanisms, weather influences, and the modulation by ENSO.

This paper is outlined as follows. Section 2 describes the datasets and methodology. The formation mechanisms and weather influences are presented in sections 3 and 4, respectively. Section 5 discusses the modulation of EP events by ENSO. The conclusions are presented in section 6 .

\section{Data and methods}

\section{a. Data}

The present study uses daily data on a $1.25^{\circ}$ grid from the Japanese 55-year Reanalysis (JRA-55) (Ebita et al. 2011; Kobayashi et al. 2015), which covers the extended winter seasons [November-March (NDJFM)] from $1958 / 59$ to $2014 / 15$. The gridded field variables at the standard pressure levels are used. These variables include tropospheric temperature, horizontal wind, geopotential height, and convective heating rate (CHR). Besides, the total column precipitable water (TCPW) and the total column water flux (TCWF) are also used. In addition, to test the sensitivity of our results to the particular CHR dataset, we use the daily interpolated outgoing longwave radiation (OLR) data provided by the National Oceanic and Atmospheric Administration (Liebmann and Smith 1996). Daily anomalies at each grid point are obtained by subtracting the seasonal cycle on that calendar day from the raw daily field. The seasonal cycle is defined by the first three Fourier harmonics of the daily climatology.
To examine the modulation of EPs by ENSO, we use the monthly (1958/59-2014/15) Extended Reconstructed Sea Surface Temperature version 4 (ERSST.v4) data (Huang et al. 2015; Liu et al. 2015; Huang et al. 2016). The ENSO phases are defined based on the ERSST.v4 SST anomalies in the Niño- 3.4 region $\left(5^{\circ} \mathrm{S}-5^{\circ} \mathrm{N}, 120^{\circ}-170^{\circ} \mathrm{W}\right)$. For El Niño (La Niña) winters, the December-February mean Niño-3.4 index must surpasses the $+0.5^{\circ} \mathrm{C}\left(-0.5^{\circ} \mathrm{C}\right)$ threshold. Based on this threshold, there are $20 \mathrm{El}$ Niño winters, 18 La Niña winters, and 19 ENSO-neutral winters in total, as shown in Table 1.

\section{b. Definitions of the EP pattern and its canonical convection pattern}

Following Athanasiadis et al. (2010) and Tan et al. (2015), the EP pattern in this study refers to the second empirical orthogonal function (EOF) of the daily nonstandardized anomaly fields of $250-\mathrm{hPa}$ zonal wind for the late winters (February-March) from 1979/80 to $2014 / 15$ over the North Pacific $\left(0^{\circ}-88.75^{\circ} \mathrm{N}, 120^{\circ} \mathrm{E}-\right.$ $105^{\circ} \mathrm{W}$ ). The daily $250-\mathrm{hPa}$ zonal wind anomaly fields are projected onto the EP pattern, and the obtained time series is normalized and used as the daily EP index (EPI). Figure 1a shows the EP pattern as the regression of the geopotential height anomaly fields at $250 \mathrm{hPa}$ upon the EPI. The positive phase of EP is defined as the situation where the subpolar anomaly over North Pacific is cyclonic.

EP's canonical convection pattern is obtained as follows. First, the lagged regression of the daily $250-\mathrm{hPa}$ convective heating rate anomalies in the tropics against the EPI is performed; then, the two-week mean (from day -13 to day 0 ) CHR anomaly pattern is made 
(Fig. 1b). We choose a two-week average because the regressed CHR anomalies vary slowly during this period and the extratropical response to tropical heating may take two weeks or so (Matthews et al. 2004; Dai et al. 2017). The positive phase of the convection pattern refers to suppressed convection over the central equatorial Pacific and enhanced convection over the Maritime Continent. The dipole convection anomaly is also detected in the field of the outgoing longwave radiation (Tan et al. 2015). The 250-hPa CHR anomalies in the domain $\left(25^{\circ} \mathrm{S}-20^{\circ} \mathrm{N}, 40^{\circ} \mathrm{E}-120^{\circ} \mathrm{W}\right)$ are projected onto the convection pattern, and the obtained time series is normalized and used as the daily convection index (CI). The sensitivity of the CI-based analyses to the particular CHR dataset is examined by obtaining a projection pattern (analogous to Fig. 1b) and CI with the OLR data. A very similar OLR projection pattern is obtained (see Fig. S1b in the online supplemental material), and the linear correlation between the OLR-based CI and the CHR-based CI is found to have a value of 0.86 , indicating that CI-based analyses are not sensitive to the particular proxy convection dataset.

\section{c. Definition and classification of EP events}

An EP event of positive (negative) polarity is defined if the EPI exceeds $1.0(-1.0)$ standard deviations at least for four consecutive days. The onset day for the positive (negative) phase of an EP event is defined as the first day on which the EPI exceeds $1.0(-1.0)$ standard deviations. The day of the peak EPI is denoted as day 0 . Two EP events of the same phase must be at least 15 days apart to ensure the independence of the samples; otherwise, the weaker event is discarded.

An EP event is identified as a convective EP event if the value of the 5-day running mean of the $\mathrm{CI}$ is greater (less) than $1.0(-1.0)$ at least once within the 10 days before the onset day of the EP event. An EP event is identified as a nonconvective EP event if the absolute value of the 5-day running mean of the $\mathrm{CI}$ is always less than 0.75 within the 10 days before the onset day of the EP event. Events that meet none of the thresholds are discarded. The choice of these thresholds is to distinguish the convective and nonconvective EP events, and to ensure that the sample size for each group is sufficiently large for composite analysis.

Based on the above criteria, we have identified 116 positive phase EP events and 116 negative phase EP events in total for the period 1958/59-2014/15 (Table 1, second column). For the positive EP, there are 48 nonconvective events and 46 convective events. For the negative EP, there are 42 nonconvective events and 46 convective events. This implies that EP events, regardless of their phases, can occur with and without the canonical convection pattern. Among the 116 positive phase EP events and 116 negative phase EP events, this study also detects a third category of EP events, which are preceded by the canonical convection pattern of opposite sign to that of EP. There are 6 positive EP events preceded by the negative phase of convection pattern and 16 negative EP events preceded by the positive phase of convection pattern. This study will exclude the last two cases for the limited sample sizes, and focus on the former four cases.

\section{d. Statistical analysis}

Several of the calculations performed in this study use linear regressions. The method that we use to evaluate statistical significance for linear regressions follows that of Kosaka et al. (2012), where the effective degrees of freedom $N_{\text {eff }}$ corresponds to

$$
N_{\text {eff }}=N /\left\{1+2 \sum_{\tau}(1-\tau / N)\left[r_{x}(\tau) r_{y}(\tau)\right]\right\},
$$

where $N$ is length of time series $X$ and $Y$, and $r_{x}$ and $r_{y}$ are the corresponding autocorrelation functions for $X$ and $Y$, with a lag of $\tau$ days.

Statistical significance of the composite analysis in this study is assessed with a Monte Carlo test by calculating 1000 randomly generated composites, with the number of composites being the same as the number of EP events. To test statistical significance, the observed composite is compared to the distribution of randomly generated composites.

\section{Formation mechanisms of EP}

We display the evolution features of the four cases of EPs through lagged composites of the $250-\mathrm{hPa}$ geopotential height anomalies (Figs. 2 and 3 ). The associated wave activity fluxes (arrows) (Takaya and Nakamura 2001) that illustrate snapshots of wave activity propagation, and the anomalous convective heating rate over the $30^{\circ} \mathrm{S}-30^{\circ} \mathrm{N}$ band (color shadings) are also shown.

\section{a. Nonconvective EP events}

Figure 2 shows the formation processes of the positive (left panels) and negative (right panels) nonconvective EPs, respectively. As expected, convection anomalies in the tropics for both phases of the nonconvective EP events are neither strong nor coherent, suggesting that tropical convection plays a minor role in the formation of the nonconvective EPs. For the positive nonconvective EP pattern (Fig. 2, left panels), it arises 

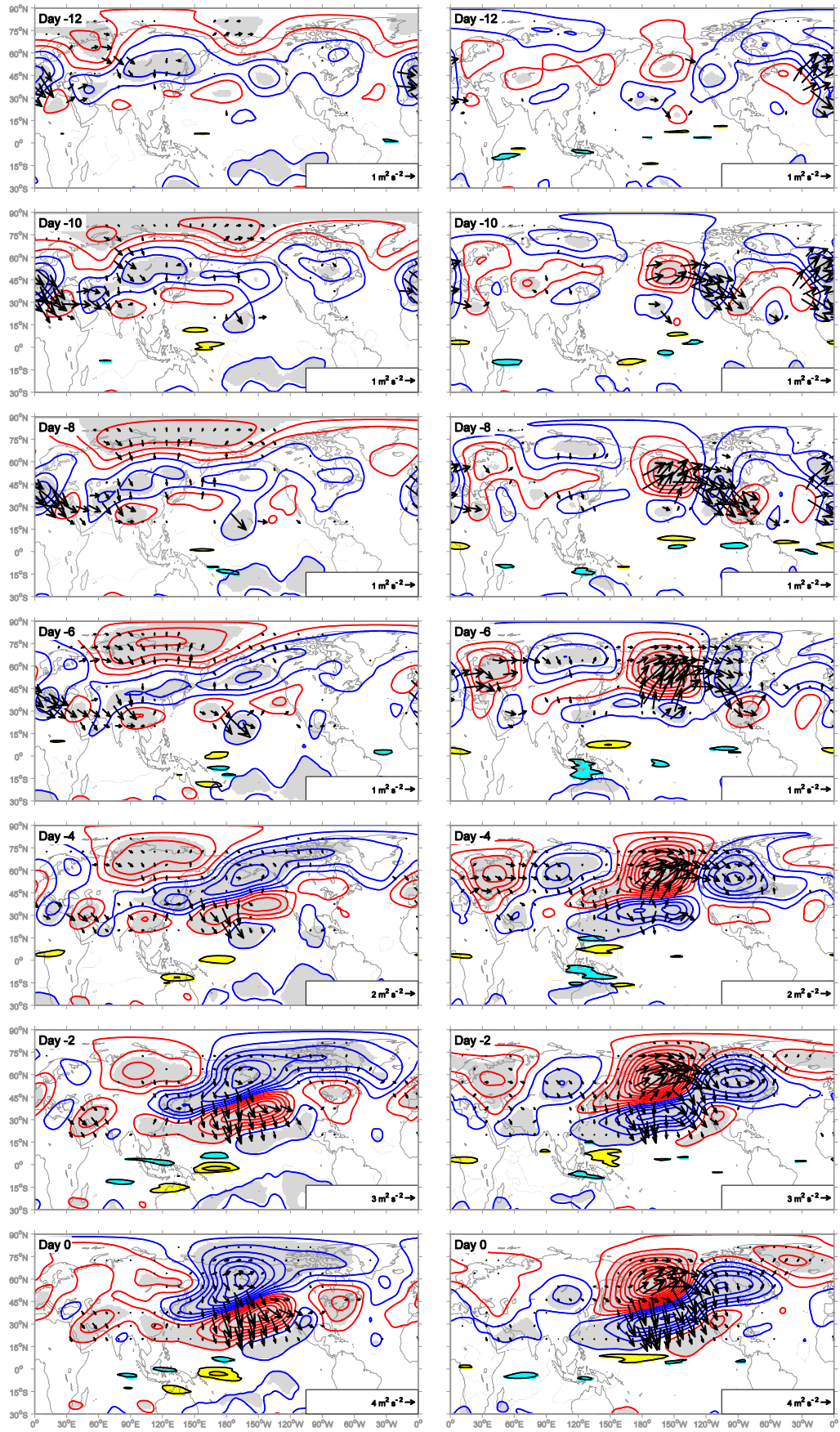

FIG. 2. Lagged composites of anomalous geopotential height at $250 \mathrm{hPa}$ based on the nonconvective (left) positive and (right) negative EP events from day -12 to day 0 with the lag days labeled in the upper-left corner of each panel. Red (blue) contours denote positive (negative) anomalies. Contours start from $\pm 10 \mathrm{~m}$ with an interval of $20 \mathrm{~m}$. Gray shadings indicate anomalies that are statistically significant at the $p<0.10$ level as determined with a two-tailed Monte Carlo test. Black contours indicate anomalous convective heating rates. Contours start from $\pm 0.5 \mathrm{~K} \mathrm{day}^{-1}$ with an interval of $0.5 \mathrm{~K} \mathrm{day}^{-1}$. Warm (cold) shadings indicate positive (negative) anomalies that are statistically significant at the $p<0.10$ level as determined with a two-tailed Monte Carlo test. Arrows represent wave activity fluxes that are statistically significant at the $p<0.10$ level at least for one component on a two-tailed Monte Carlo test. Scaling for wave activity fluxes is given at the bottom-right corner for each panel (units: $\mathrm{m}^{2} \mathrm{~s}^{-2}$ ). 

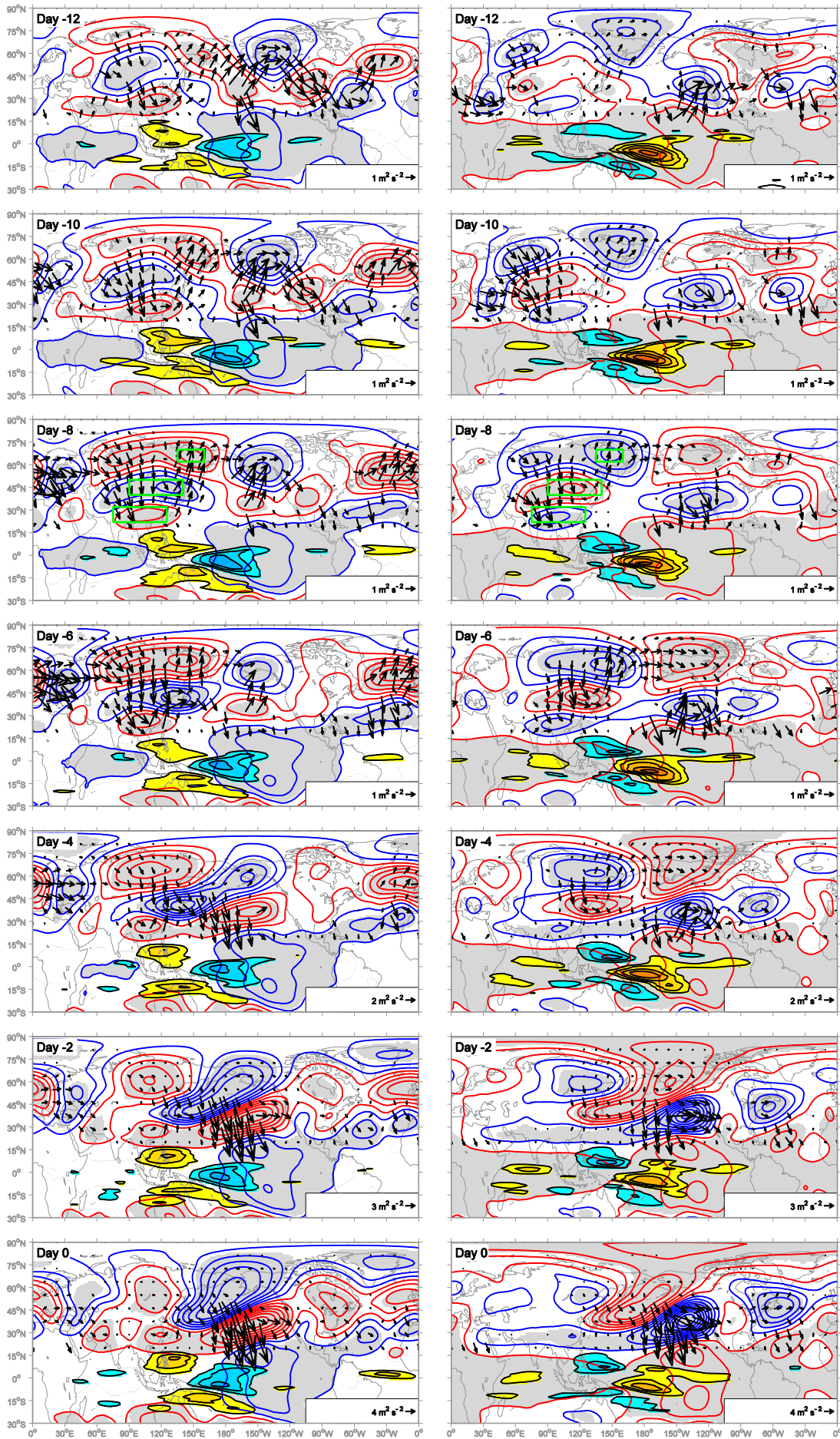

FIG. 3. As in Fig. 2, but for the convective EP events. At lag day -8 , the three green rectangular boxes located along the coast of Asia, representing $22^{\circ}-32^{\circ} \mathrm{N}, 75^{\circ}-125^{\circ} \mathrm{E} ; 40^{\circ}-$ $50^{\circ} \mathrm{N}, 90^{\circ}-140^{\circ} \mathrm{E}$; and $62^{\circ}-70^{\circ} \mathrm{N}, 135^{\circ}-160^{\circ} \mathrm{E}$, denote the domains where the normalized 250 $\mathrm{hPa}$ geopotential height anomalies are area-averaged to obtain the East Asian wave train (EAWT) index used for the bars in Fig. 4. [The EAWT index is simply proposed as follows: $\left.I_{\text {EAWT }}=Z_{250\left(22^{\circ}-32^{\circ} \mathrm{N}, 75^{\circ}-125^{\circ} \mathrm{E}\right)}^{*}-Z_{250\left(40^{\circ}-50^{\circ} \mathrm{N}, 90^{\circ}-140^{\circ} \mathrm{E}\right)}^{*}+Z_{250\left(62^{\circ}-70^{\circ} \mathrm{N}, 135^{\circ}-160^{\circ} \mathrm{E}\right)}^{*}\right]$ 
from a wave train originating from the Arctic region and propagating southeastward to North Pacific (from day -12 to day -6 in Fig. 2, left panels). From day -6 , this wave train intensifies and expands steadily and evolves into the EP pattern at around day -4. The EP pattern matures at day 0 .

For the negative nonconvective EP pattern (Fig. 2, right panels), it initiates from a wave train originating from the eastern North Pacific and propagating southeastward across North America (day -10 in Fig. 2, right panels). From day -8 to day -4 , under the influence of the wave train over Eurasia, the subpolar anticyclonic center of the Pacific wave train intensifies rapidly; meanwhile, the cyclonic anomaly centered around $30^{\circ} \mathrm{N}$ amplifies. The full EP pattern forms at around day -2 and matures at day 0 .

A plausible explanation for the wave train originating from the Arctic region observed in the growth of the positive nonconvective EPs (day -10 in Fig. 2, left panels) and the wave train originating from the eastern North Pacific observed in the growth of the negative nonconvective EPs (day -10 in Fig. 2, right panels) may be the diabatic heating anomalies over the Arctic Ocean and North Pacific Ocean. On the one hand, as can be seen from Fig. S2 (left panels), for the positive nonconvective EPs, from day -12 to day -6 , over the Barents-Kara Seas, there are significantly positive total column precipitable water anomalies (warm shadings), indicating that the wave train originating from the Arctic region during these days may be attributed to the forcing by diabatic heating anomalies. Furthermore, the total column water flux vectors do not show a statistically significant signal of atmospheric water flux convergence; hence, the moisture for Arctic may originate from the Arctic Ocean (i.e., evaporation from the Arctic Ocean) rather than from the midlatitude troposphere. Further insights into the role of sea ice variability over the Barents-Kara Seas are hampered by the relatively short duration of the observational record of sea ice data. By contrast, for the negative nonconvective EPs (Fig. S2, right panels), there are no significant TCPW anomalies over the Arctic region, consistent with the absence of the wave train originating from the Arctic region (Fig. 2, right panels). On the other hand, it can be seen from Fig. S3 (right panels) that, for the negative nonconvective EPs, during their life cycles, in the eastern North Pacific, there are significantly positive SST anomalies (warm shadings), indicating that the wave train originating from the eastern North Pacific may also be attributed to the forcing by diabatic heating anomalies. By contrast, for the positive nonconvective EPs (Fig. S3, left panels), there are no significant SST anomalies over North Pacific, consistent with the absence of the wave train over there (Fig. 2, left panels). These observational evidences suggest that Arctic Ocean and North Pacific Ocean may exert impacts on the formation of the nonconvective EP events. However, future works based on numerical models need to be conducted to make causal claims between the extratropical oceans and the EP variability.

\section{b. Convective EP events}

From lagged composites for the convective EPs (Fig. 3), we see that the canonical convection pattern exists throughout their life cycles. The convection dipole is believed to play an important role in the formation of EP (Tan et al. 2015). As both phases of the convective EPs exhibit similar formation features, we will mainly discuss the positive convective EP case (Fig. 3, left panels).

As can be seen, from day -12 to day 0 (Fig. 3, left panels), for the positive convective EPs, the suppressed convection over the central equatorial Pacific forces an upper-tropospheric cyclonic pair residing in both hemispheres straddling the equator-a Rossby wave response to the tropical convective heating (Matsuno 1966; Gill 1980). The northern anomalous cyclone located south of Hawaii evolves finally into the subtropical secondary center of the EP pattern (day 0 in Fig. 3, left panels). Meanwhile, from day -12 to day -8 , an extratropical Rossby wave train propagates northward along the coast of East Asia toward eastern Siberia and then turns southeastward to the Gulf of Alaska (referred to as the East Asian wave train), giving rise to an anomalous anticyclone over North Asia and two anomalous cyclones over Japan and Alaska, respectively. At around day -4 , the two anomalous cyclones over Japan and Alaska begin to merge, and evolve into the northern primary center of the EP pattern later on. As a result, the full EP pattern forms at around day -4 and matures at day 0. As in the case of the nonconvective EP pattern, a southeastward propagating Eurasian wave train is also observed in the developing stage of the positive convective EP pattern. Through reinforcing the East Asian wave train, the Eurasian wave train contributes to the formation of the EP pattern, especially the amplification of the anticyclone over North Asia (from day -12 to day -2 in Fig. 3, left panels). The latter causes significantly warm anomalies over North Asia (as will be shown in Fig. 7). In addition, the Eurasian wave train also contributes to the formation of the southern primary center of the EP pattern (day -4 in Fig. 3, left panels).

The negative convective EP pattern shows an evolution process similar to that for the positive convective EP pattern (Fig. 3, right panels). A prominent difference is 

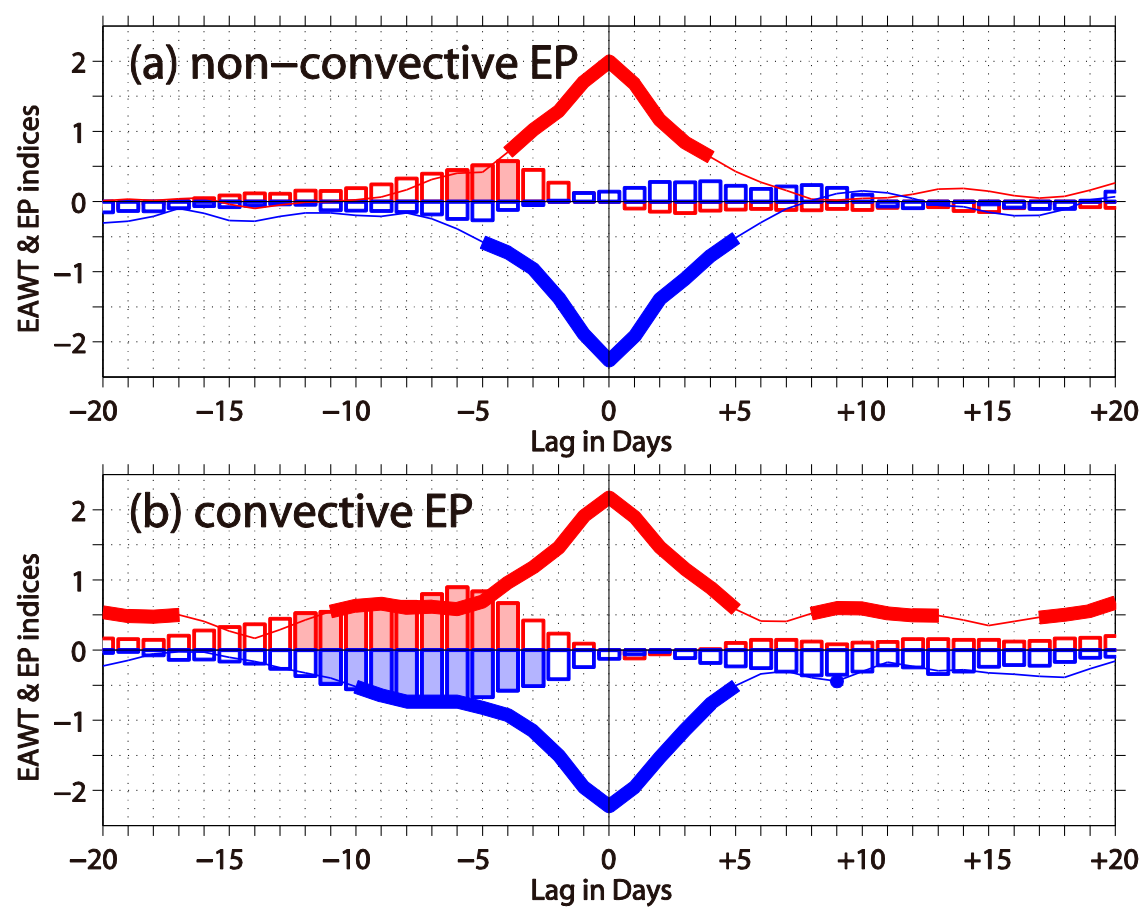

FIG. 4. Lagged composites of the normalized EP (curves) and EAWT (bars) indices for (a) nonconvective and (b) convective EP events. The red curves (bars) correspond to composites for the positive EP events and the blue curves (bars) for the negative EP events. Thick lines correspond to lag days for which the composite value is statistically significant at the $p<$ 0.05 level determined with a one-tailed Monte Carlo test. Shaded bars correspond to lag days for which the composite value is statistically significant at the $p<0.10$ level determined with a two-tailed Monte Carlo test.

that, for the negative convective EP pattern, there are wave activity fluxes emanating from the anomalous central subtropical Pacific anticyclone and propagating northeastward toward North America (from day -12 to day -4 in Fig. 3, right panels). These wave activity fluxes contribute to the development of EP's southern primary center.

\section{c. Time-scale features}

We next examine the time-scale characteristics of the $\mathrm{EP}$ events. If we define the lifetime of an EP event as corresponding to the time period over which its amplitude is statistically significant at the $p<0.05$ level determined with a one-tailed Monte Carlo test, we can see that the EP events persist for a period of about 2 weeks (Fig. 4 and Table 2). To be specific, the nonconvective EP events last for about 10 days (Table 2 and curves in Fig. 4a), and the convective EP events persist for 16-17 days (Table 2 and curves in Fig. 4b), with the latter lasting for one more week than the former. The difference in time-scale features may be attributed to the influence from tropical convection during the life cycles of the convective EP events, since the tropical convection anomalies are usually more persistent than the EP pattern. Moreover, Fig. 4 shows that, during the development stages of the nonconvective EP events, the East Asian wave train anomalies are weak and insignificant (bars in Fig. 4a), while their counterparts for the convective EP events are strong and persistent (bars in Fig. 4b), indicating that the influence of tropical convection on the convective EP events may be attributed to the occurrence of the East Asian wave train.

\section{d. Synoptic eddy forcing}

We now explore the role of synoptic-scale (with a period less than 10 days) transient eddies in the growth

TABLE 2. The lifetime of EP events with and without the canonical tropical convection pattern, defined as the time period over which the amplitude of the EP is statistically significant at the $p<0.05$ level determined with a one-tailed Monte Carlo test.

\begin{tabular}{cc}
\hline \hline Nonconvective $\mathrm{EP}^{+}$ & Convective $\mathrm{EP}^{+}$ \\
\hline 9 (days) & 17 (days) \\
Nonconvective $\mathrm{EP}^{-}$ & Convective $\mathrm{EP}^{-}$ \\
\hline 11 (days) & 16 (days) \\
\hline
\end{tabular}



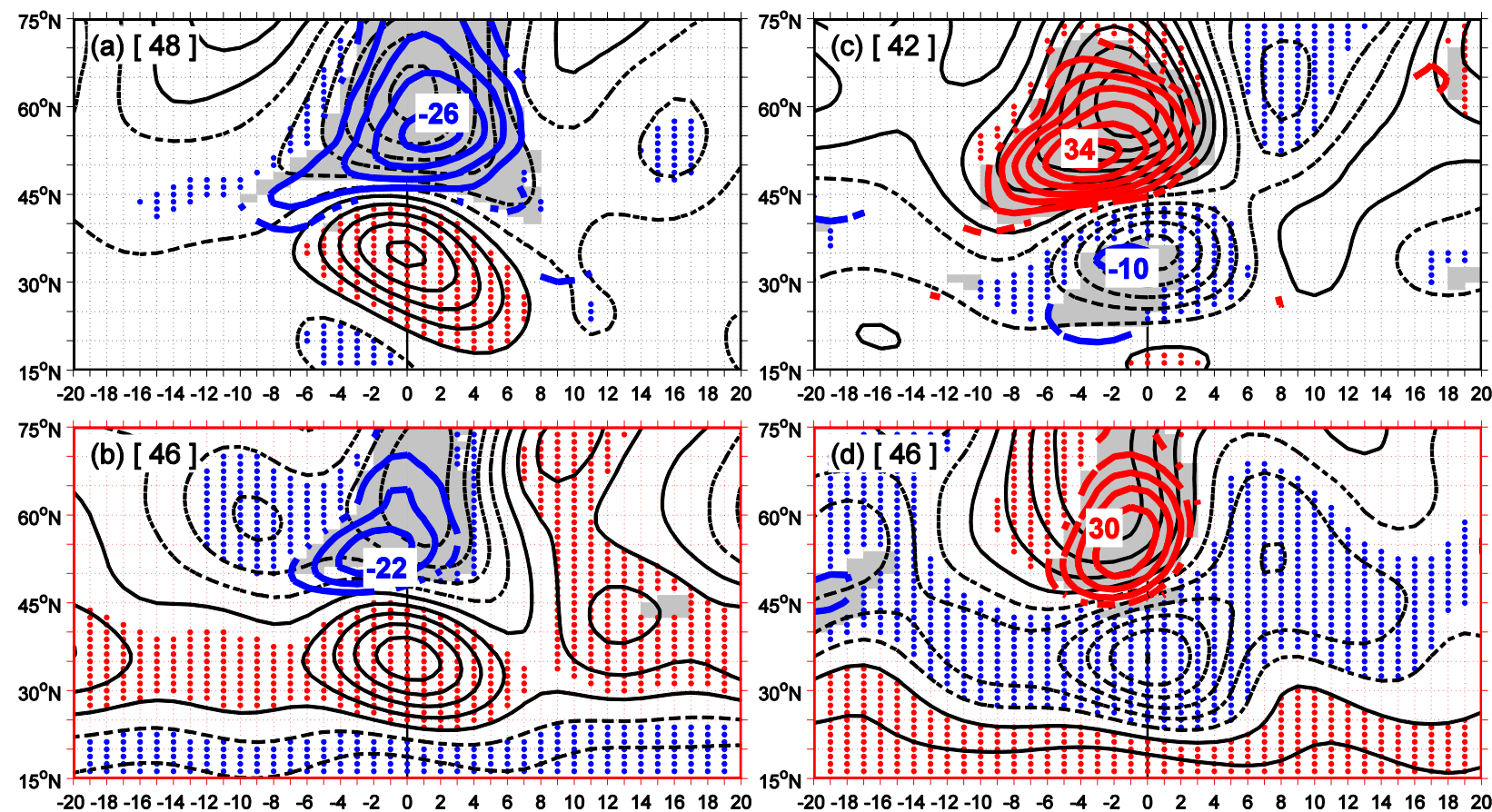

FIG. 5. Composites of anomalous 250-hPa geopotential height (black contours) and barotropic forcing by synoptic-scale transient eddies (with a period less than 10 days) represented as geopotential height tendency (colored contours) zonally averaged over the North Pacific sector $\left(180^{\circ}-120^{\circ} \mathrm{W}\right)$ from lag -20 to +20 days for (a) nonconvective $\mathrm{EP}^{+}$, (b) convective $\mathrm{EP}^{+}$, (c) nonconvective $\mathrm{EP}^{-}$, and (d) convective EP $^{-}$events, respectively. For geopotential height anomalies, contours start from $\pm 10 \mathrm{~m}$ with an interval of $20 \mathrm{~m}$ and zero lines are omitted; solid (dashed) contours indicate positive (negative) values. Forcing by transient eddies displayed are statistically significant at the $p<0.10$ level on a two-tailed Monte Carlo test. Contours start from $\pm 2 \mathrm{~m} \mathrm{day}^{-1}$ with an interval of $4 \mathrm{~m}_{\text {day }}{ }^{-1}$ and zero lines are omitted. Warm (cold) stippling denotes positive (negative) geopotential height anomalies that are statistically significant at the $p<0.10$ level based on a two-tailed Monte Carlo test, where forcing by transient eddies are insignificant. Shading denotes anomalies of both quantities that are statistically significant at the $p<0.10$ level based on a two-tailed Monte Carlo test.

and decay of the EP pattern. For this purpose, we show composites of the geopotential height (black contours) and the barotropic forcing by transient eddies represented as geopotential height tendency (colored contours) at $250 \mathrm{hPa}$ zonally averaged over the North Pacific sector $\left(180^{\circ}-120^{\circ} \mathrm{W}\right)$ from lag -20 to +20 days (Fig. 5), since the later can be regarded as an upper bound on the net eddy forcing of local geopotential height tendency at the tropopause level (Lau and Holopainen 1984; Lau and Nath 1991; Takaya and Nakamura 2005).

As can be seen in Fig. 5, for the positive nonconvective EP composites (Fig. 5a), there is a nearly complete overlap in the distribution of the significantly anomalous negative geopotential height tendency associated with the synoptic-scale eddies and the significantly anomalous negative geopotential height associated with EPs (centered near $60^{\circ} \mathrm{N}$; shading and cold stippling in Fig. 5a) for the period from day -10 to day +8 . This suggests that the synoptic-scale transient eddies contribute significantly to the growth and the maintenance of the positive nonconvective EP events. By contrast, for the positive convective EP composites (Fig. 5b), there is some overlap in the distribution of the significantly anomalous negative geopotential height tendency associated with the synoptic-scale eddies and the significantly anomalous negative geopotential height associated with EPs (centered near $60^{\circ} \mathrm{N}$; shading and cold stippling in Fig. 5b) for the period from day -7 to day +4 . However, before day -7 when the synoptic-scale eddies start to contribute significantly to the growth of the positive convective EP events, the significantly anomalous negative geopotential height has existed for 5 days (centered near $60^{\circ} \mathrm{N}$; dashed black contours and cold stippling in Fig. 5b). Above all, the weak but significant meridional tripole-like geopotential height anomalies, which project onto the typical EP pattern, arise well before the feedback from synoptic-scale eddies takes place, with the two lower-latitude centers appearing as early as day -20 (black contours and stippling in Fig. 5b). This picture is consistent with the EP life cycle shown in Tan et al. (2015). In particular, the EP pattern is first excited by tropical convection, and then undergoes further growth with the aid of positive feedback from transient eddies. As can be 
seen in Figs. 5c and 5d, the negative phase composites generally give consistent results with those of the positive phase.

The above results suggest that while feedback forcing from synoptic-scale transient eddies plays important roles in driving and maintaining both types of EP events (Fig. 5), the roles differ in strength and persistence between the nonconvective and convective EP events, with the former being more persistent and more intense. As to why there are differences in the feedback forcing from transient eddies between the two types of EP events, an important point here is that the definition of an EP event is that the amplitude of the EP index must exceed one standard deviation. For the convective EP events, tropical convection is strong, which can excite a weak EP-like wave field before the forcing from transient eddies takes place. By contrast, for the nonconvective EP events, the tropical convection has little influence; therefore, in order to account for the absent contribution from tropical convection and for the EP index to exceed the threshold value, a stronger and longer-lasting feedback forcing from transient eddies is expected to take place.

\section{Weather influence of $\mathbf{E P}$}

The strong and extensive anomalous centers of EPs tend to cause strong anomalous lower-layer flows that take the form of a cyclone/anticyclone pair over North Pacific and the coast areas (Figs. S4 and S5). These anomalous flows together with the anomalous flows over Asia and North America bring cold or/and warm air into Asia, North Pacific, and North America, and cause strong near-surface temperature anomalies over there. The intensity, extent, and persistence of the temperature anomalies over these regions vary with the EP's types, phases, and stages in their life cycles, as illustrated in the lagged composites shown in Figs. 6 and 7 .

Over East Asia, for the positive (negative) convective EPs (from day -8 to day 0 in Fig. 7), it is the anomalous northerly (southerly) along the coast of East Asia that strengthens (weakens) the climatological EAWM circulation and causes cold (warm) anomalies over East Asia. Meanwhile, the anomalous flows associated with the anomalous anticyclonic (cyclonic) flow over North Asia give rise to the near-surface warm (cold) anomalies over North Asia. Consequently, the near-surface temperature anomalies over Asia assume a meridional dipole structure with its two anomalous centers located over North Asia and East Asia, respectively, which occurs mainly in the growth and peak stages of both phases of the convective EPs from day -8 to day 0 (Fig. 7). The maximum amplitude of the temperature anomalies over East Asia exceeds $3 \mathrm{~K}$ (day -4 in Fig. 7, left panel). For the nonconvective EPs, the temperature anomalies are weaker, more restricted, and of shorter durations (Fig. 6). The remarkable difference in temperature anomalies over Asia between the convective and nonconvective EP events may be attributed to the propagation of the extratropical Rossby wave train along the coast of Asia (referred to as the East Asian wave train) for the convective EP events. The East Asian wave train, which causes strong height anomalies over Japan and North Asia, and therefore anomalous meridional winds along the coast of East Asia and strong flow anomalies over North Asia for the convective EP events, is absent in the case of the nonconvective EP events. Consequently, although the EP pattern can exert significant influence on East Asian weather even in the absence of the East Asian wave train (EAWT), the convective EPs associated with the EAWT have stronger impacts than the nonconvective EPs.

The general EP-EAWM relationship can be quantitatively described by calculating the correlation coefficients between the seasonal-mean [calculated by taking a December-February (DJF) average] EPI and the EAWM indices. If we use two EAWM indices, $I_{\mathrm{Jhun}}$ and $I_{\mathrm{Chen}}$, which are based on the upper-tropospheric zonal wind shear (Jhun and Lee 2004) and the lowertropospheric wind (Chen et al. 2000), respectively, we obtain that EP is significantly correlated with EAWM ( $r=0.41$ and 0.60 for $I_{\mathrm{Jhun}}$ and $I_{\mathrm{Chen}}$, respectively, both significant at the $p<0.01$ level as determined with a twotailed Student's $t$ test), which explains about $16 \%$ or $36 \%$ of the total variation of EAWM on the interannual time scale. Furthermore, it will be shown that, on the interannual time scale, the EP pattern is significantly and inversely correlated with ENSO, implying that the EP pattern may contribute partially, at least, to the outof-phase relationship between ENSO and EAWM. The fact that the surface winds and temperature anomalies, as well as the East Asian wave train, can be reproduced in the absence of the ENSO-induced background winter monsoon anomalies via other ways supports this point of view. Figures S6 and S7 show composites of the evolution processes (Fig. S6) and surface temperature anomalies (Fig. S7) for EPs that take place during ENSO-neutral winters (hereafter denoted as "convective EP/ENSO-neutral events" and "nonconvective EP/ENSO-neutral events"), where there are no significant ENSO-induced background flow anomalies. Table 1 indicates that there are four convective $\mathrm{EP}^{+} /$ ENSO-neutral events and seven convective $\mathrm{EP}^{-} /$ ENSO-neutral events, so as to enlarge the sample size, and because the anomalies associated with positive and negative EP events tend to have opposite features, we construct EP/ENSO-neutral events composites by 

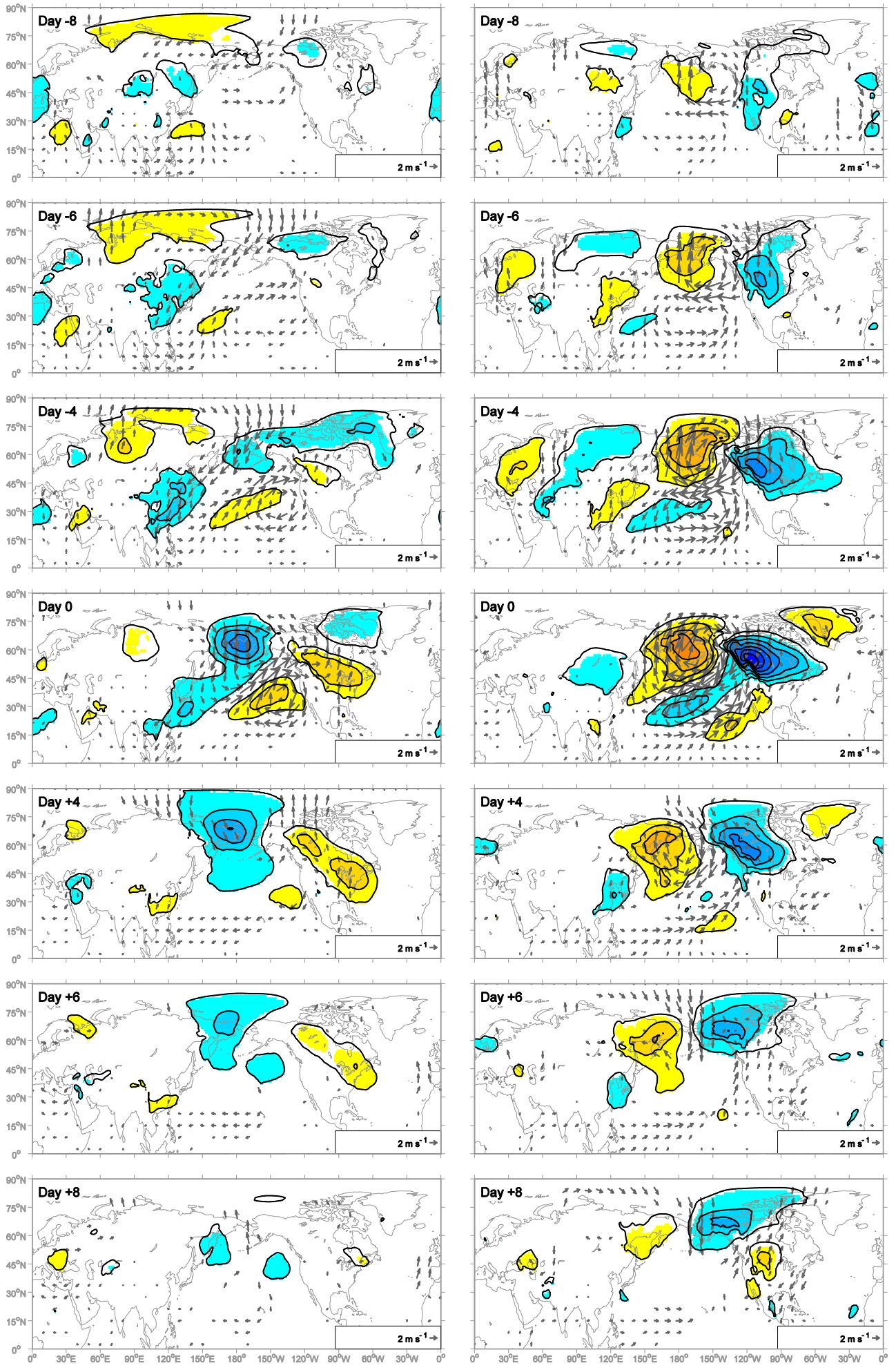

FIG. 6. Lagged composites of anomalous $850-\mathrm{hPa}$ air temperature (contours and shading) based on the nonconvective (left) positive and (right) negative EP events from day -8 to day +8 with the lag days labeled in the upper-left corner of each panel. Contours start from $\pm 1.0 \mathrm{~K}$ with an interval of $1.0 \mathrm{~K}$. Warm (cold) shadings indicate positive (negative) anomalies that are statistically significant at the $p<0.10$ level as determined with a two-tailed Monte Carlo test. Arrows represent anomalous $850-\mathrm{hPa}$ winds that are statistically significant at the $p<0.10$ level for at least one component on a two-tailed Monte Carlo test. Scaling for winds is given at the bottom-right corner for each panel (units: $\mathrm{m} \mathrm{s}^{-1}$ ). 

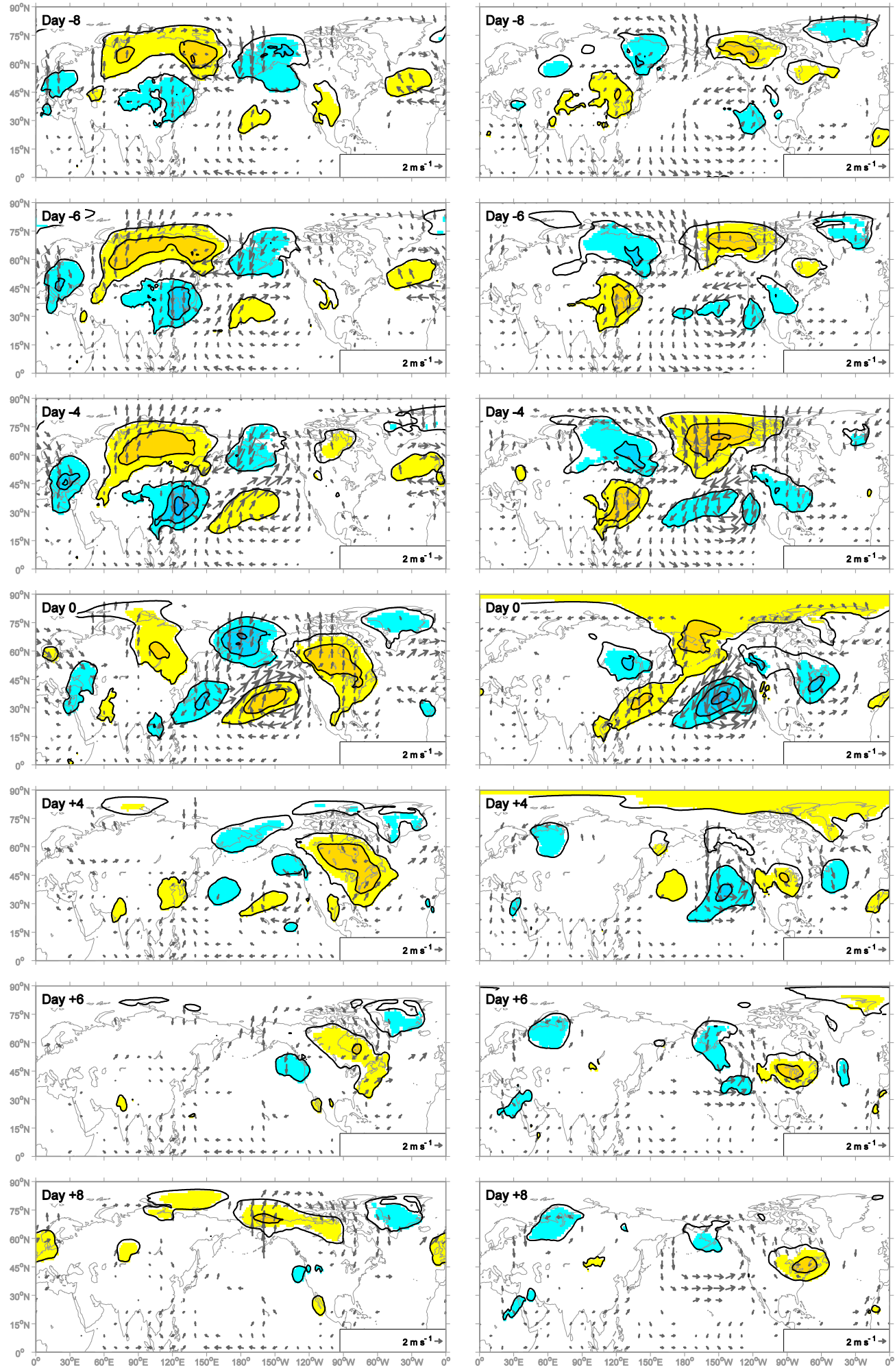

FIG. 7. As in Fig. 6, but for the convective EP events. 
subtracting $\mathrm{EP}^{-} / \mathrm{ENSO}$-neutral from $\mathrm{EP}^{+} / \mathrm{ENSO}$-neutral composites. First of all, it can be seen from Fig. S6 (right panels) that, in the growth stage of the convective EP/ENSO-neutral events, both the dipole-like convection anomalies and evolution of circulation (e.g., the East Asian wave train at around day -10) can be well identified, which are absent in the case of the nonconvective EP/ENSO-neutral events (Fig. S6, left panels). Besides, as can be seen in Fig. S7, in ENSOneutral winters, both the convective and nonconvective EP composites exhibit significant temperature anomalies over East Asia, with the former (Fig. S7, right panels) being more intense and more persistent than the latter (Fig. S7, left panels). These results suggest that the East Asian temperature anomalies shown in Figs. 6 and 7 are attributed to the development of EPs, rather than to the manifestations of ENSO-induced background anomalies via other ways; and the differences in East Asian temperature anomalies between the convective and nonconvective EP composites are attributed to the differences between the two types of EPs, rather than to the differences in the background flows.

Corresponding to the giant anomalous cyclonic/ anticyclonic pair over North Pacific, the near-surface temperature anomalies over there generally assume a meridional dipole-like structure with one extremum located over the Bering Sea and the other located north of Hawaii (day 0 in Figs. 6 and 7). In the case of the nonconvective EP events, the northern center of the dipole is stronger and longer-lasting than the southern center (Fig. 6), especially for the negative nonconvective EPs. To be specific, for the negative nonconvective EPs, the warm anomalies over the Bering Sea last for two weeks or so (from day -8 to day +6 in Fig. 6 , right panels) with the maximum amplitude exceeding $4 \mathrm{~K}$ (day 0 in Fig. 6, right panels). These strong and persistent warm anomalies may cause significant sea ice anomalies over the wintertime Bering Sea (Yuan et al. 2015).

By contrast, the structure of near-surface air temperature anomalies over North America varies with the EP types and phases. Specifically, for the positive nonconvective EPs (Fig. 6, left panels), the near-surface air temperature anomalies over North America exhibit a transition from a meridional dipole-like structure at day -4 to a monopole structure at day +6 , with the warm anomalies over the United States persisting for 10 days or so (from day -4 to day +6 in Fig. 6, left panels); for the positive convective EPs (Fig. 7, left panels), the warm anomalies over North America assume a monopole structure and persist for 10 days or so (from day -4 to day +6 in Fig. 7, left panels). For the negative nonconvective EPs (Fig. 6, right panels), the cold anomalies over North America also assume a monopole structure for about two weeks (from day -8 to day +6 in Fig. 6, right panels), and the minimum anomalies reach as low as $-7 \mathrm{~K}$ (day 0 in Fig. 6, right panel). Such strong and persistent cold anomalies could bring about severe cold storms to North America; for the negative convective EPs (Fig. 7, right panels), marginally significant cooling is observed over the United States from day -6 to day 0 , followed by weak warm anomalies from day +4 to day +8 (Fig. 7 , right panels).

\section{The ENSO modulation}

\section{a. General characteristics of the modulation by ENSO}

We have shown that EP has substantial impacts on wintertime weather over East Asia and North America (Figs. 6 and 7). Here we further show that, despite the fluctuations on the subseasonal time scale, the EP pattern is also significantly and inversely correlated with ENSO (specifically, the Niño-3.4 index) on the interannual time scale $(r=-0.69$ calculated by taking a DJF average, significant at the $p<0.01$ level as determined with a twotailed Student's $t$ test), and the modulation of EP events by ENSO is realized through its influence on the frequency of occurrence of EPs. Table 1 shows the frequencies of occurrence for four cases of EPs. Table 1 does suggest a strong preference of EPs' frequency of occurrence for different ENSO phases: The positive EP events tend to occur significantly more often during La Niña (3.22 events per winter) and less often during El Niño (1.15 events per winter), with respect to the climatology (2.04 events per winter). Furthermore, the frequency in La Niña is significantly higher than that in El Niño winters. For the negative EP, it occurs more often in El Niño (2.70 events per winter) and less often in La Niña (1.11 events per winter), and the former is significantly higher than the latter. However, for the nonconvective EPs, both phases occur more often in ENSO-neutral winters than the climatology; they occur with similar frequencies during El Niño and La Niña, and both are lower than the climatology (failing to pass the statistical test except for the negative phase in La Niña). These results suggest that the difference in frequencies between La Niña and El Niño for the total EPs cannot be attributed to the modulation of ENSO on the nonconvective EPs. In contrast, the convective EPs are strongly biased toward particular phases of ENSO, with $89 \%$ (41/46) of the positive convective EPs occurring in La Niña winters, and $83 \%$ (38/46) of the negative convective EPs occurring in El Niño winters. The above facts suggest that the modulation of EPs by ENSO is mainly realized through modulating the frequency of occurrence of the convective EPs. 

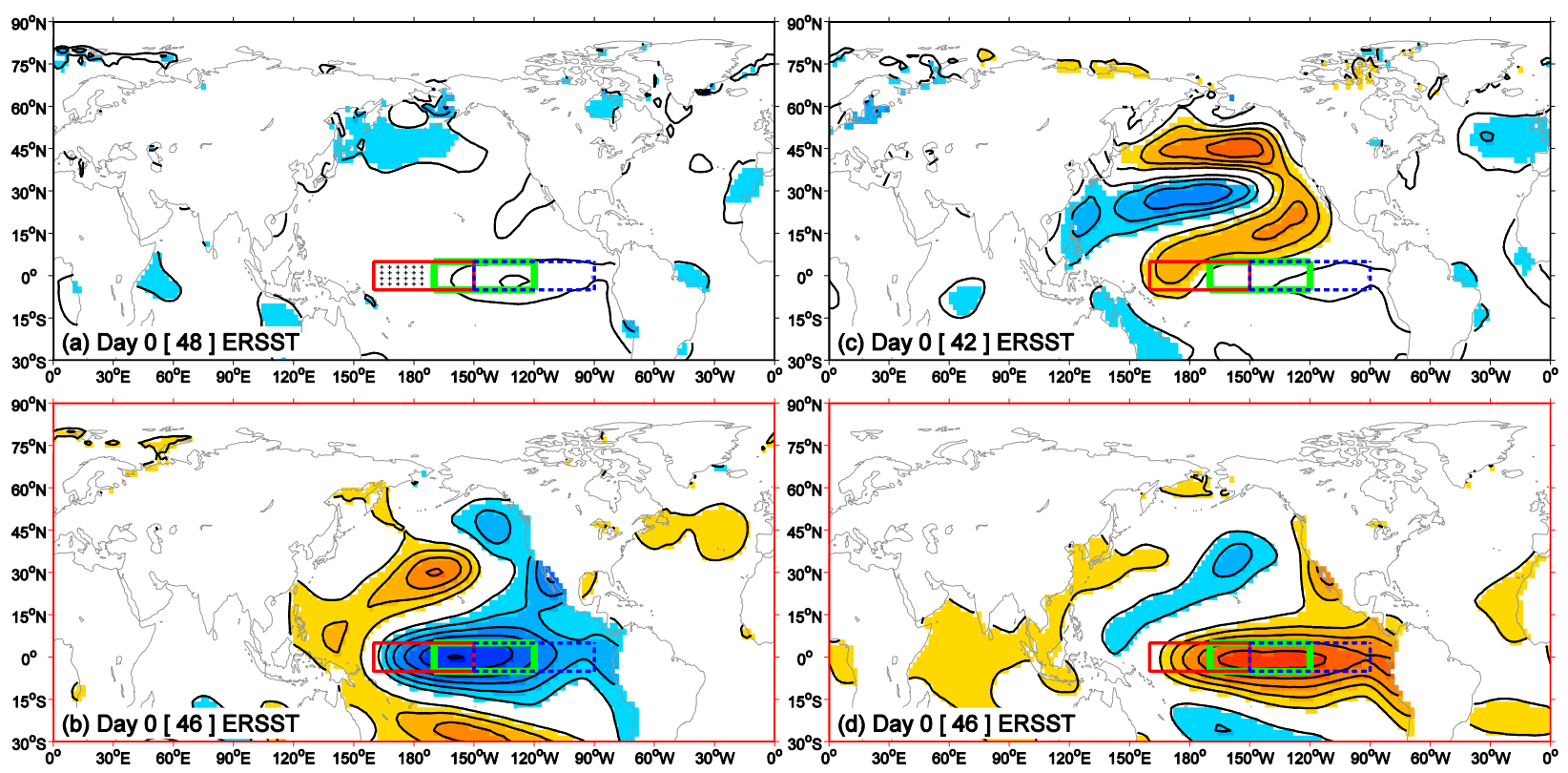

FIG. 8. Composites of anomalous SST fields at day 0 for (a) nonconvective $\mathrm{EP}^{+}$, (b) convective $\mathrm{EP}^{+}$, (c) nonconvective $\mathrm{EP}^{-}$, and (d) convective $\mathrm{EP}^{-}$events, respectively. For nonconvective EPs, contours start from $\pm 0.1 \mathrm{~K}$ with an interval of $0.1 \mathrm{~K}$ and zero lines are omitted. For convective EPs, contours start from $\pm 0.2 \mathrm{~K}$ with an interval of $0.2 \mathrm{~K}$ and zero lines are omitted. Red (blue) shadings indicate positive (negative) anomalies that are statistically significant at the $p<0.10$ level on a two-tailed Monte Carlo test. The green rectangular box over the equatorial Pacific $\left(5^{\circ} \mathrm{S}-5^{\circ} \mathrm{N}, 170^{\circ}-120^{\circ} \mathrm{W}\right)$ denotes the Niño-3.4 region. The red rectangular box over the central equatorial Pacific $\left(5^{\circ} \mathrm{S}-5^{\circ} \mathrm{N}, 160^{\circ} \mathrm{E}-150^{\circ} \mathrm{W}\right)$ denotes the Niño-4 region. The blue rectangular box over the eastern equatorial Pacific $\left(5^{\circ} \mathrm{S}-5^{\circ} \mathrm{N}, 150^{\circ}-\right.$ $\left.90^{\circ} \mathrm{W}\right)$ denotes the Niño-3 region. In (a), the region marked with pluses $\left(5^{\circ} \mathrm{S}-5^{\circ} \mathrm{N}, 160^{\circ} \mathrm{E}-170^{\circ} \mathrm{W}\right)$ denotes the Niño- $4 \mathrm{w}$ region, where SST anomalies are averaged to calculate the Niño-4w index.

The modulation of the convective EPs by ENSO can be reasonably understood as follows. During El Niño winters, the positive sea surface temperature (SST) anomalies over the central Pacific and negative SST anomalies over the western Pacific, as well as the ascending and descending motion associated with the anomalous Walker circulation (Kumar et al. 2010; Zhang et al. 2015), set conditions highly favorable for the occurrence of the negative phase of EP's canonical convection pattern. Consistent with this, La Niña tends to set conditions favorable for the occurrence of the positive phase of EP's canonical convection pattern. To assess whether this is indeed the case, we first examine the SST anomalies associated with EPs (Fig. 8). For the entire 57-winter period (1958/59-2014/15), daily SST anomalies are constructed from linear interpolation of the monthly ERSST.v4 data. As expected, for the positive (negative) convective EPs, there are significant cold (warm) anomalies over the Niño-3.4 region (the green rectangular box in Figs. 8b,d). By contrast, for the nonconvective EPs, no significant SST anomalies can be observed over the Niño3.4 region (the green rectangular box in Figs. 8a,c). Next, we examine the modulation of EP's canonical convection pattern by ENSO. As can be seen from the histograms of CI (Fig. 9), during El Niño (La Niña) winters, there is a shift to the left (right), indicating an increased frequency of the negative (positive) phase of EP's canonical convection pattern. No obvious shift is observed in ENSO-neutral winters (Fig. 9c). This is further confirmed by the statistically significant correlation coefficient between ENSO and CI $(r=-0.91$ calculated by taking a DJF average, significant at the $p<0.01$ level as determined with a two-tailed Student's $t$ test). Consequently, most of the negative convective EP events occur in El Niño, and most of the positive convective EP events occur in La Niña (Table 1).

\section{b. Dependency on ENSO diversity}

In the following, we further examine whether the modulation of EPs by ENSO depends on ENSO diversity. As this study investigates the modulation of the eastern Pacific teleconnection pattern (EP) by ENSO, so as to avoid confusion, we will not use eastern Pacific (EP) and central Pacific (CP) El Niño (La Niña) to distinguish El Niño (La Niña) types; instead, we will refer to them as "cold tongue" and "date line" El Niños (La Niñas), respectively. First of all, we divide all 20 (18) El Niños (La Niñas) shown in Table 1 into two categories, that is, cold tongue and date line El Niños ( $\mathrm{La}$ Niñas). Among all of the $20 \mathrm{El}$ Niños (18 La Niña) shown in Table 1, an El Niño (a La Niña) event is classified as a date line event if the amplitude of the SST 

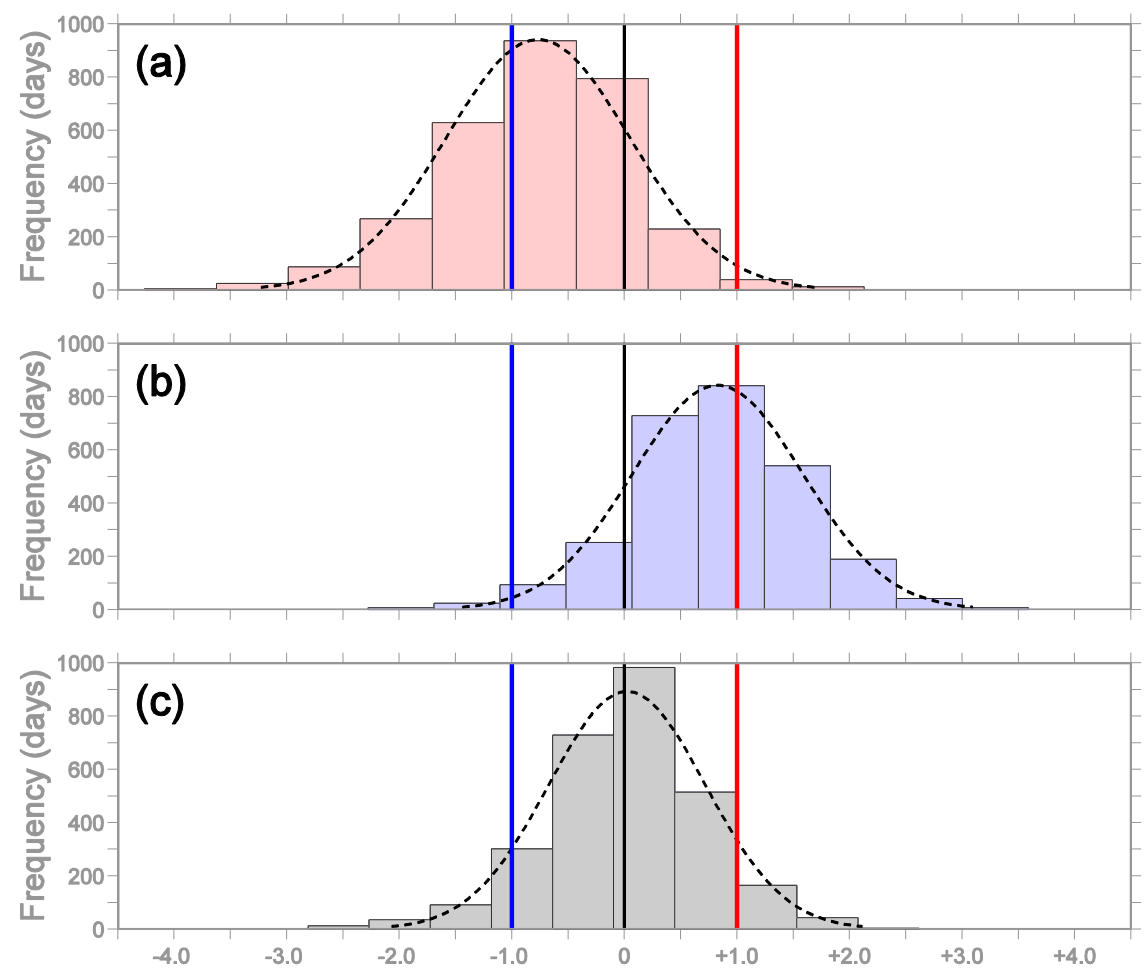

FIG. 9. Histograms of CI (bars) for (a) El Niño, (b) La Niña, and (c) ENSO-neutral winters over 1958/59-2014/15, along with a normal density function with parameters estimated from the data (dashed curves). The red (blue) vertical line indicates $1.0(-1.0)$ standard deviation of CI.

anomalies (SSTA) averaged over the Niño-4 region exceeds that over the Niño-3 region; consistently, cold tongue events are characterized by the amplitude of Niño-3 SSTA exceeding that of the Niño-4 SSTA. As a result, we identify 12 cold tongue El Niños and 8 date line El Niños, as well as 11 cold tongue La Niñas and 7 date line La Niñas. On the basis of that, we further calculate the frequencies of occurrence of the convective EPs during both types of El Niño (La Niña). As can be seen (Table 3), for the positive convective EP events, the frequency of occurrence is 1.45 events per winter during cold tongue La Niña, and 3.57 events per winter during date line La Niña. Both are greater than the climatological value ( 0.81 events per winter as shown in Table 1). In addition, the frequency of occurrence during date line La Niña ( 3.57 events per winter) is 2.5 times greater than that during cold tongue La Niña (1.45 events per winter). Consistently, for the negative convective EP events, the frequency of occurrence is 1.67 events per winter during cold tongue El Niño and 2.25 events per winter during date line El Niño. Both are greater than the climatological value ( 0.81 events per winter as shown in Table 1). Moreover, the frequency of occurrence during date line El Niño (2.25 events per winter) is approximately 1.5 times greater than that during cold tongue El Niño (1.67 events per winter). These results suggest that, although both types of La Niña (El Niño) are favorable for the occurrence of the positive (negative) convective EP events, the date line La Niña (El Niño) may be more efficient than the cold tongue La Niña (El Niño), with the caveat that the distinction between the two types of ENSO remains a debate (Capotondi et al. 2015).

Above all, we also investigate the potential linkage between the negative nonconvective EP events and warming in the central equatorial Pacific. As can be seen in Fig. 8c, for the negative nonconvective EP events, the associated SST anomalies extend from the Northern Hemisphere eastern subtropics to the central equatorial Pacific. Therefore, it is possible that warming in the central equatorial Pacific may be associated with an increased frequency of negative nonconvective EP events, which can induce extremely cold spells over the northern United States and western Canada (as low as $-7 \mathrm{~K}$; day 0 in Fig. 6, right panels). In this sense, the negative nonconvective EP events may be of particular interest for subseasonal-to-seasonal prediction of wintertime weather over North America. To assess whether this is indeed the case, we examine the modulation of the frequency of occurrence of the negative nonconvective EP 
TABLE 3. The number of years for El Niño (La Niña), followed by the number and frequency (unit: events per winter) of the convective EP events detected in El Niño (La Niña) over 1958/59-2014/15. General El Niño (La Niña) corresponds to the years where the Niño3.4 index surpasses the $+0.5^{\circ} \mathrm{C}\left(-0.5^{\circ} \mathrm{C}\right)$ threshold. Date line (cold tongue) El Niño corresponds to the years where the Niño-3.4 index surpasses the $+0.5^{\circ} \mathrm{C}$ threshold, and the amplitude of the Niño-4 (Niño-3) index exceeds that of the Niño-3 (Niño-4) index. Date line (cold tongue) La Niña corresponds to the years where the Niño-3.4 index surpasses the $-0.5^{\circ} \mathrm{C}$ threshold, and the amplitude of the Niño-4 (Niño-3) index exceeds that of the Niño-3 (Niño-4) index.

\begin{tabular}{lccc}
\hline \hline 1958/59-2014/15 & General & Cold tongue & Date line \\
\hline El Niño & $20^{\mathrm{a}}$ & $12^{\mathrm{b}}$ & $8^{\mathrm{c}}$ \\
Convective EP & $38(1.90)$ & $20(1.67)$ & $18(2.25)$ \\
La Niña & $18^{\mathrm{d}}$ & $11^{\mathrm{e}}$ & $7^{\mathrm{f}}$ \\
Convective $\mathrm{EP}^{+}$ & $41(2.28)$ & $16(1.45)$ & $25(3.57)$ \\
\hline
\end{tabular}

${ }^{a}$ The 20 general El Niño winters are 1958/59, 1963/64, 1965/66, 1968/69, 1969/70, 1972/73, 1976/77, 1977/78, 1979/80, 1982/83, 1986/87, 1987/88, 1991/92, 1994/95, 1997/98, 2002/03, 2004/05, 2006/07, 2009/10, and 2014/15.

b The 12 cold tongue El Niño winters are 1963/64, 1965/66, 1969/70, 1972/73, 1976/77, 1979/80, 1982/83, 1986/87, 1991/92, 1997/98, 2002/03, and 2006/07.

${ }^{\mathrm{c}}$ The 8 date line El Niño winters are 1958/59, 1968/69, 1977/78, 1987/88, 1994/95, 2004/05, 2009/10, and 2014/15.

d The 18 general La Niña winters are 1964/65, 1967/68, 1970/71, 1971/ 72, 1973/74, 1974/75, 1975/76, 1984/85, 1988/89, 1995/96, 1998/99, 1999/00, 2000/01, 2005/06, 2007/08, 2008/09, 2010/11, and 2011/12.

${ }^{e}$ The 11 cold tongue La Niña winters are 1964/65, 1967/68, 1970/71, 1971/72, 1974/75, 1975/76, 1984/85, 1995/96, 1999/00, 2005/06, and 2007/08.

${ }^{f}$ The 7 date line La Niña winters are 1973/74, 1988/89, 1998/99, 2000/ 01, 2008/09, 2010/11, and 2011/12.

events by warming in the central equatorial Pacific. It can be seen from Fig. $8 \mathrm{c}$ that the positive SST anomalies over tropical Pacific mainly locate in the western part of the Niño-4 region (hereafter denoted as the Niño-4w region, with " $w$ " denoting the western part of the Niño-4 region), where there is no overlap with the Niño-3.4 region. So as to focus on the SST variability over the Niño-4w region, instead of following the Niño-3/4 index method (Kug et al. 2009; Yeh et al. 2009), an alternative Niño-4w index method is used: A "warm Niño-4w" winter is identified if its SSTA averaged over the Niño$4 \mathrm{w}$ region $\left(5^{\circ} \mathrm{S}-5^{\circ} \mathrm{N}, 160^{\circ} \mathrm{E}-170^{\circ} \mathrm{W}\right.$; see the region marked with pluses in Fig. 8a) exceeds one standard deviation, and exceeds the amplitude of the SSTA averaged over the Niño-3.4 region $\left(5^{\circ} \mathrm{S}-5^{\circ} \mathrm{N}, 170^{\circ}-120^{\circ} \mathrm{W}\right)$. In this way, we obtain five years for the warm Niño-4w events, including 1987, 1990, 2003, 2004, and 2014, where there are eight negative nonconvective EP events in total. Therefore, the frequency of occurrence of the negative nonconvective EP events during warm Niño$4 \mathrm{w}$ winters (1.60 events per winter) is 2.0 times greater than the climatological value ( 0.74 events per winter as shown in Table 1). These results suggest that warming in the Niño- $4 \mathrm{w}$ region $\left(5^{\circ} \mathrm{S}-5^{\circ} \mathrm{N}, 160^{\circ} \mathrm{E}-170^{\circ} \mathrm{W}\right)$ may be effective in triggering the negative nonconvective EP events, and thus may be associated with an enhanced likelihood of extremely cold spells over the northern United States and western Canada.

Furthermore, we notice that for the negative nonconvective EP events, there are significant SST anomalies in the North Pacific (Fig. 8c), whereas SST anomalies are weak and insignificant in the case of the positive nonconvective EP events (Fig. 8a). The extratropical SST anomalies, through surface heat fluxes, may modulate lower-tropospheric temperature anomalies, and thus result in active eddy forcing, as demonstrated in Xiao et al. (2016). Therefore, the asymmetric feature observed in the North Pacific SST anomalies between the two polarities of nonconvective EPs may be potentially related to the difference exhibited in the peak amplitudes of nonconvective EPs (Fig. 4a), which is larger for the negative EPs (approaches 2.5 standard deviations) than for the positive EPs (around 2.0 standard deviations), as supported by the stronger eddy forcing for the former (Fig. 5c) than for the latter (Fig. 5a).

\section{Discussion and conclusions}

This study provides observational evidence highlighting the role of the atmospheric internal feedback forcing from synoptic-scale eddies in the amplification and persistence of the EP pattern, and illustrating the remote influence of tropical Pacific variability on the occurrence of the EP pattern through the East Asian wave train, which can be attributed to the modulation of the EPs' canonical convection pattern by ENSO. This observational study also demonstrates that the EP patterns, regardless of their phases, can occur with and without the canonical convection pattern. The convective EP events persist for one more week than the nonconvective EP events, as the former persists for about 17 days and the latter about 10 days. Moreover, forcing by synoptic-scale transient eddy fluxes takes on a more prominent role in driving and maintaining the nonconvective EP events than they do during the life cycles of the convective EP events. It is noteworthy that, although causal relationships between tropical convection and the formation of the convective EP events cannot be claimed based solely on time-lag relationships, our observational results are suggestive of driving of the convective EPs by tropical convection, considering the differences in time scales and forcing by transient eddies between the two types of EP events. Moreover, we calculated the two-week mean (over the period from day -13 to day 0 ) of lagged regressions of unfiltered daily CHR anomalies against the PNA index (Fig. S8b). 
For a better comparison, Fig. 1b is included as Fig. S8a. As can be seen, the regressed convection anomalies associated with EP (Fig. S8a) are more intense than those associated with PNA (Fig. S8b). The results suggest that, comparing with PNA, EP is more closely related to tropical convective heating. As the causal relationship between PNA and tropical convection has been verified in many idealized modeling papers (Matthews et al. 2004; Seo and Son 2012; Yoo et al. 2012; Goss and Feldstein 2015), it is to be expected that tropical convective anomalies may make a substantial contribution to the formation of the EP pattern since EP is more closely related to tropical convective heating than PNA.

Besides the time scales and feedback forcing from synoptic-scale transient eddies, there are also differences in weather influence and modulation by ENSO between the convective and nonconvective EP events. On the one hand, the convective EP events, regardless of their phases, cause more intense and more persistent surface air temperature anomalies over East Asia than the nonconvective EP events. Moreover, the frequencies of occurrence for the convective EP events are significantly modulated by ENSO. In particular, in El Niño winters, more negative and fewer positive convective EP events tend to occur; consequently, more warm and fewer cold weather events are expected in East Asia. In La Niña winters, the reverse is true. On the other hand, the nonconvective EP events, in their negative phases, can cause extremely cold anomalies (as low as $-7 \mathrm{~K}$ ) over the northern United States and western Canada. Furthermore, when there are positive SST anomalies over the central equatorial Pacific, the frequencies of occurrence for the negative nonconvective EPs increase and thus an enhanced likelihood of extremely cold spells over North America may be expected.

Acknowledgments. We thank three anonymous reviewers for their helpful comments which improved the manuscript considerably. This research is supported by Chinese NSF Grants 41875065 and 41130962. YD acknowledges support from the EU H2020 BlueAction (GA 727852) project for this work. The JRA-55 reanalysis data used in this study were obtained from https://rda.ucar.edu/datasets/ds628.0/. The NOAA OLR data were obtained from https://www.esrl.noaa.gov/psd/ data/gridded/data.interp_OLR.html. The NOAA ERSST. $\mathrm{v} 4$ data were obtained from https://www.esrl.noaa.gov/psd/ data/gridded/data.noaa.ersst.v4.html.

\section{REFERENCES}

Athanasiadis, P. J., J. M. Wallace, and J. J. Wettstein, 2010: Patterns of wintertime jet stream variability and their relation to the storm tracks. J. Atmos. Sci., 67, 1361-1381, https://doi.org/ 10.1175/2009JAS3270.1.
Barnston, A. G., and R. E. Livezey, 1987: Classification, seasonality and persistence of low-frequency atmospheric circulation patterns. Mon. Wea. Rev., 115, 1083-1126, https:// doi.org/10.1175/1520-0493(1987)115<1083:CSAPOL >2.0. $\mathrm{CO} ; 2$.

Capotondi, A., and Coauthors, 2015: Understanding ENSO diversity. Bull. Amer. Meteor. Soc., 96, 921-938, https://doi.org/ 10.1175/BAMS-D-13-00117.1.

Chen, W., H.-F. Graf, and R. Huang, 2000: The interannual variability of East Asian winter monsoon and its relation to the summer monsoon. Adv. Atmos. Sci., 17, 48-60, https://doi.org/ 10.1007/s00376-000-0042-5.

Dai, Y., S. B. Feldstein, B. Tan, and S. Lee, 2017: Formation mechanisms of the Pacific-North American teleconnection with and without its canonical tropical convection pattern. J. Climate, 30, 3139-3155, https://doi.org/10.1175/JCLI-D-16-0411.1.

Ebita, A., and Coauthors, 2011: The Japanese 55-year Reanalysis "JRA55": An interim report. SOLA, 7, 149-152, https://doi.org/10.2151/ sola.2011-038.

Gill, A. E., 1980: Some simple solutions for heating-induced tropical circulation. Quart. J. Roy. Meteor. Soc., 106, 447-462, https://doi.org/10.1002/qj.49710644905.

Goss, M., and S. B. Feldstein, 2015: The impact of the initial flow on the extratropical response to Madden-Julian oscillation convective heating. Mon. Wea. Rev., 143, 1104-1121, https://doi.org/ 10.1175/MWR-D-14-00141.1.

Green, P. M., D. M. Legler, C. J. Miranda V, and J. J. O'Brien, 1997: The North American climate patterns associated with El Niño-Southern Oscillation. COAPS Project Rep. Series 97-1, https://www.coaps.fsu.edu/papers/north_american southern_oscillation/.

Halpert, M. S., and C. F. Ropelewski, 1992: Surface temperature patterns associated with the Southern Oscillation. J. Climate, 5, 577-593, https://doi.org/10.1175/1520-0442(1992)005<0577: STPAWT $>2.0 . \mathrm{CO} ; 2$.

Horel, J. D., and J. M. Wallace, 1981: Planetary-scale atmospheric phenomena associated with the Southern Oscillation. Mon. Wea. Rev., 109, 813-829, https://doi.org/10.1175/1520-0493 (1981) $109<0813$ :PSAPAW > 2.0.CO;2.

Huang, B., and Coauthors, 2015: Extended Reconstructed Sea Surface Temperature version 4 (ERSST.v4). Part I: Upgrades and intercomparisons. J. Climate, 28, 911-930, https://doi.org/ 10.1175/JCLI-D-14-00006.1.

- and Coauthors, 2016: Further exploring and quantifying uncertainties for Extended Reconstructed Sea Surface Temperature (ERSST) version 4 (v4). J. Climate, 29, 3119-3142, https://doi.org/10.1175/JCLI-D-15-0430.1.

Huang, R., J. Chen, and G. Huang, 2007: Characteristics and variations of the East Asian monsoon system and its impacts on climate disasters in China. Adv. Atmos. Sci., 24, 993-1023, https://doi.org/10.1007/s00376-007-0993-x.

— _ - L. Wang, and Z. Lin, 2012: Characteristics, processes, and causes of the spatio-temporal variabilities of the East Asian monsoon system. Adv. Atmos. Sci., 29, 910-942, https://doi.org/ 10.1007/s00376-012-2015-x.

Jhun, J., and E. Lee, 2004: A new East Asian winter monsoon index and associated characteristics of the winter monsoon. J. Climate, 17, 711-726, https://doi.org/10.1175/1520-0442(2004)017<0711: ANEAWM $>2.0 . \mathrm{CO} ; 2$.

Kim, J. W., S. W. Yeh, and E. C. Chang, 2014: Combined effect of El Niño-Southern Oscillation and Pacific decadal oscillation on the East Asian winter monsoon. Climate Dyn., 42, 957-971, https://doi.org/10.1007/s00382-013-1730-z. 
Kobayashi, S., and Coauthors, 2015: The JRA-55 reanalysis: General specifications and basic characteristics. J. Meteor. Soc. Japan, 93, 5-48, https://doi.org/10.2151/jmsj.2015-001.

Kosaka, Y., J. S. Chowdary, S. P. Xie, Y. M. Min, and J. Y. Lee, 2012: Limitations of seasonal predictability for summer climate over East Asia and the northwestern Pacific. J. Climate, 25, 7574-7589, https://doi.org/10.1175/JCLI-D-12-00009.1.

Kug, J.-S., F.-F. Jin, and S.-I. An, 2009: Two types of El Niño events: Cold tongue El Niño and warm pool El Niño. J. Climate, 22, 1499-1515, https://doi.org/10.1175/2008JCLI2624.1.

Kumar, A., B. Jha, and M. L'Heureux, 2010: Are tropical SST trends changing the global teleconnection during La Niña? Geophys. Res. Lett., 37, L12702, https://doi.org/10.1029/ 2010GL043394.

Lau, N.-C., and E. O. Holopainen, 1984: Transient eddy forcing of the time-mean flow as identified by geopotential tendencies. J. Atmos. Sci., 41, 313-328, https://doi.org/10.1175/ 1520-0469(1984)041<0313:TEFOTT>2.0.CO;2.

, and M. J. Nath, 1991: Variability of the baroclinic and barotropic transient eddy forcing associated with monthly changes in the midlatitude storm tracks. J. Atmos. Sci., $\mathbf{4 8}$, 2589-2613, https://doi.org/10.1175/1520-0469(1991)048<2589: VOTBAB $>2.0 . \mathrm{CO} ; 2$.

- and — 2000: Impact of ENSO on the variability of the Asian-Australian monsoons as simulated in GCM experiments. J. Climate, 13, 4287-4309, https://doi.org/10.1175/ 1520-0442(2000)013<4287:IOEOTV>2.0.CO;2.

$\mathrm{Li}, \mathrm{C}$., 1990: Interaction between anomalous winter monsoon in East Asia and El Niño events. Adv. Atmos. Sci., 7, 36-46, https://doi.org/10.1007/BF02919166.

Liebmann, B., and C. A. Smith, 1996: Description of a complete (interpolated) outgoing longwave radiation dataset. Bull. Amer. Meteor. Soc., 77, 1275-1277.

Linkin, M., and S. Nigam, 2008: The North Pacific Oscillation-west Pacific teleconnection pattern: Mature-phase structure and winter impacts. J. Climate, 21, 1979-1997, https://doi.org/ 10.1175/2007JCLI2048.1.

Liu, W., and Coauthors, 2015: Extended Reconstructed Sea Surface Temperature version 4 (ERSST.v4). Part II: Parametric and structural uncertainty estimations. J. Climate, 28, 931-951, https://doi.org/10.1175/JCLI-D-14-00007.1.

Matsuno, T., 1966: Quasi-geostrophic motion in the equatorial area. J. Meteor. Soc. Japan, 44, 25-43, https://doi.org/10.2151/ jmsj1965.44.1_25.

Matthews, A. J., B. J. Hoskins, and M. Masutani, 2004: The global response to tropical heating in the Madden-Julian oscillation during northern winter. Quart. J. Roy. Meteor. Soc., 130, 19912012, https://doi.org/10.1256/qj.02.123.

Renwick, J. A., and J. M. Wallace, 1996: Relationships between North Pacific blocking, El Niño, and the PNA pattern. Mon. Wea. Rev., 124, 2071-2076, https://doi.org/10.1175/1520-0493(1996)124<2071: RBNPWB $>2.0 . \mathrm{CO} ; 2$.

Ropelewski, C. F., and M. S. Halpert, 1986: North American precipitation and temperature patterns associated with the El Niño/Southern Oscillation (ENSO). Mon. Wea. Rev., 114, 2352-2362, https://doi.org/10.1175/1520-0493(1986)114<2352: NAPATP $>2.0 . \mathrm{CO} ; 2$.

, and — 1987: Global and regional scale precipitation patterns associated with El Niño/Southern Oscillation. Mon. Wea. Rev., 115, 1606-1626, https://doi.org/10.1175/1520-0493(1987) $115<1606$ :GARSPP $>2.0$. CO;2.
Seo, K.-H., and S.-W. Son, 2012: The global atmospheric circulation response to tropical diabatic heating associated with the Madden-Julian oscillation during northern winter. J. Atmos. Sci., 69, 79-96, https://doi.org/10.1175/2011JAS3686.1.

Takaya, K., and H. Nakamura, 2001: A formulation of a phaseindependent wave-activity flux for stationary and migratory quasi geostrophic eddies on a zonally varying basic flow. J. Atmos. Sci., 58, 608-627, https://doi.org/10.1175/1520-0469(2001)058<0608: AFOAPI $>2.0 . \mathrm{CO} ; 2$.

$\longrightarrow$, and - 2005: Geographical dependence of upper-level blocking formation associated with intraseasonal amplification of the Siberian high. J. Atmos. Sci., 62, 4441-4449, https:// doi.org/10.1175/JAS3628.1.

Tan, B., J. Yuan, Y. Dai, S. B. Feldstein, and S. Lee, 2015: The linkage between the eastern Pacific teleconnection pattern and convective heating over the tropical western Pacific. J. Climate, 28, 5783-5794, https://doi.org/10.1175/JCLI-D-14-00568.1.

Trenberth, K. E., G. W. Branstator, D. Karoly, A. Kumar, N.-C. Lau, and C. Ropelewski, 1998: Progress during TOGA in understanding and modeling global teleconnections associated with tropical sea surface temperatures. J. Geophys. Res., 103, 14 291-14324, https://doi.org/10.1029/97JC01444.

Wallace, J. M., and D. S. Gutzler, 1981: Teleconnections in the geopotential field during the Northern Hemisphere winter. Mon Wea. Rev., 109, 784-812, https://doi.org/10.1175/1520-0493(1981) $109<0784$ :TITGHF $>2.0 . \mathrm{CO} ; 2$

Wang, B., R. Wu, and X. Fu, 2000: Pacific-East Asian teleconnection: How does ENSO affect East Asian climate? J. Climate, 13, 1517-1536, https://doi.org/10.1175/1520-0442(2000)013<1517: PEATHD $>2.0 . \mathrm{CO} ; 2$.

Wang, L., W. Chen, and R. Huang, 2008: Interdecadal modulation of PDO on the impact of ENSO on the East Asian winter monsoon. Geophys. Res. Lett., 35, L20702, https://doi.org/ 10.1029/2008GL035287.

Webster, P. J., and S. Yang, 1992: Monsoon and ENSO: Selectively interactive systems. Quart. J. Roy. Meteor. Soc., 118, 877-926, https://doi.org/10.1002/qj.49711850705.

Xiao, B., Y. Zhang, X.-Q. Yang, and Y. Nie, 2016: On the role of extratropical air-sea interaction in the persistence of the southern annular mode. Geophys. Res. Lett., 43, 8806-8814, https://doi.org/10.1002/2016GL070255.

Yeh, S.-W., J.-S. Kug, B. Dewitte, M.-H. Kwon, B. P. Kirtman, and F.-F. Jin, 2009: El Niño in a changing climate. Nature, 461, 511-514, https://doi.org/10.1038/nature08316.

— , and Coauthors, 2018: ENSO atmospheric teleconnections and their response to greenhouse gas forcing. Rev. Geophys. 56, 185-206, https://doi.org/10.1002/2017RG000568.

Yoo, C., S. Lee, and S. B. Feldstein, 2012: Arctic response to an MJO-like tropical heating in an idealized GCM. J. Atmos. Sci., 69, 2379-2393, https://doi.org/10.1175/JAS-D-11-0261.1.

Yuan, J., B. Tan, S. B. Feldstein, and S. Lee, 2015: Wintertime North Pacific teleconnection patterns: Seasonal and interannual variability. J. Climate, 28, 8247-8263, https://doi.org/10.1175/JCLI-D-14-00749.1.

Zhang, R., A. Sumi, and M. Kimoto, 1996: Impact of El Niño on the East Asian monsoon: A diagnostic study of the '86/87 and '91/ 92 events. J. Meteor. Soc. Japan, 74, 49-62, https://doi.org/ 10.2151/jmsj1965.74.1_49.

, T. Li, M. Wen, and L. Liu, 2015: Role of intraseasonal oscillation in asymmetric impacts of El Niño and La Niña on rainfall over southern China in boreal winter. Climate Dyn., 45, 559-567, https://doi.org/10.1007/s00382-014-2207-4. 